\title{
FUTURE WAR/FUTURE BATTLESPACE: THE STRATEGIC ROLE OF AMERICAN \\ LANDPOWER
}

\author{
Steven Metz \\ Raymond A. Millen
}

March 2003 